\title{
Should Heartbeats/Training Session Be Considered When Comparing the Cardiovascular Benefits of High-Intensity Interval Aerobic and Moderate-Intensity Continuous Training? A Critical Appraisal
}

Jhennyfer Aline Lima Rodrigues, Stella Vieira Philbois, Tábata de Paula Facioli, Ada Clarice Gastaldi and Hugo Celso Dutra de Souza* ${ }^{*}$

\begin{abstract}
The prescription of physical training as a therapeutic measure in the treatment and control of chronic degenerative diseases, mainly cardiovascular disease and metabolic disease, is an increasingly used clinical approach, often preceding the pharmacological prescription. Despite the advances in exercise physiology and cardio functional performance in recent decades, the main challenge is to identify the most appropriate modality, intensity, and training volume for each pathophysiological situation. In this case, the superiority of high-intensity interval training (HIIT) over moderate-intensity continuous training (MICT) has been questioned, since many studies have shown similar results in the different physiological parameters evaluated, especially regarding cardiorespiratory fitness, cardiovascular autonomic control, and cardiac morpho functionality. The cause of conflicting results observed by different studies may be related to standardization, application, and comparison of the two protocols. HIIT would have a higher number of heartbeats compared to MICT, when maintaining high heart rate is disregarded. In this since, our hypothesis for the greatest gains in cardiorespiratory fitness and in the autonomic and cardiovascular adaptations promoted by HIIT is based on the higher volume of training performed as a function of the higher number of heartbeats per unit of time, since the intermittence was calculated based on a percentage of maximum heart rate or reserve heart rate. Nevertheless, the intermittency between the established heart rate percentages is not necessarily accompanied by the intermittent heart rate. Therefore, considering and matching the number of heartbeats performed per training session in both models seems to be a more appropriate way to compare the two training protocols.
\end{abstract}

Keywords: Cardiovascular disease, Physical training, Heartbeat amplitude, Shear stress, Cardiorespiratory fitness

\footnotetext{
*Correspondence: hugocds@fmrp.usp.br

Department of Health Sciences, Exercise Physiology Laboratory, Ribeirão

Preto Medical School, University of São Paulo, Av. Bandeirantes, 3900 - Vila

Monte Alegre, Ribeirão Preto, SP 14049-900, Brazil
}

\section{Springer Open}

(๑) The Author(s). 2020 Open Access This article is licensed under a Creative Commons Attribution 4.0 International License, which permits use, sharing, adaptation, distribution and reproduction in any medium or format, as long as you give appropriate credit to the original author(s) and the source, provide a link to the Creative Commons licence, and indicate if changes were made. The images or other third party material in this article are included in the article's Creative Commons licence, unless indicated otherwise in a credit line to the material. If material is not included in the article's Creative Commons licence and your intended use is not permitted by statutory regulation or exceeds the permitted use, you will need to obtain permission directly from the copyright holder. To view a copy of this licence, visit http://creativecommons.org/licenses/by/4.0/. 


\section{Key Points}

1. Heartbeats/training session appears to be an important consideration when comparing the cardiovascular benefits of high-intensity interval training (HIIT) versus those of moderate-intensity continuous training (MICT).

2. The fact that HIIT training is associated with a higher number of heartbeats than MICT, when maintaining high heart rate is disregarded, might explain the superior cardiovascular benefits of HIIT.

\section{Introduction}

The prescription of physical training as a therapeutic measure in the treatment and control of chronic degenerative diseases, mainly cardiovascular disease, is an increasingly used clinical approach, often preceding the pharmacological prescription. However, despite the advances in exercise physiology and cardio functional performance in recent decades, the main challenge is to identify the most appropriate modality, intensity, and training volume for each pathophysiological situation such as hypertension, diabetes, obesity, stroke, cancer, and others. The benefits of increased physical activity/ exercise training, particularly as they lead to increased cardiorespiratory fitness, result in improved prognosis in a large spectrum of metabolic diseases and cardiovascular disease [1].

\section{High-Intensity Interval Training over Moderate- Intensity Continuous Training}

In this sense, different options of physical training have been aimed to promote greater gains for the patient, mainly because supervised exercise is recommended as the first line of treatment for non-communicable chronic disease. This is the case with high-intensity interval training (HIIT). Therefore, knowing the cardiovascular responses and cardiovascular risk involved in performing this type of exercise is relevant for these patients [2]. HIIT consists of alternating periods of intensive aerobic exercise with periods of active or passive recovery [3-5]. Some authors suggest that the benefits of this training modality might be seen in a single session as well as in the long-term, outperforming gains compared to moderate-intensity continuous training (MICT) [6-8]. The main idea for the higher gains from HIIT pointed out by these authors is that during the high-intensity period, there is a high cardiac demand, close to maximum pumping capacity, and consequently, maximum oxygen uptake (VO2max) that may bring greater cardiovascular benefits when compared to MICT $[5,9,10]$.

However, the superiority of HIIT over MICT has been questioned, since many studies have shown similar results in the different physiological parameters evaluated, especially regarding cardiorespiratory fitness (VO2peak and VO2max), cardiovascular autonomic control, and cardiac morpho functionality [11-14]. The cause of conflicting results observed by different studies may be related to standardization, application, and comparison of the two protocols. In this case, most studies compared the two modalities, HIIT and MICT, adjusting the training volume by time in minutes, since the daily session of HIIT was stipulated with a shorter time, aiming to equalize to the MICT energy expenditure, having as main reference the expected heart rate level for each intensity. However, our hypothesis for the greatest gains in cardiorespiratory fitness and in the autonomic and cardiovascular adaptations promoted by HIIT in some studies is based on the higher volume of training performed as a function of the higher number of heartbeats per unit of time, since the intermittence was calculated based on a percentage of maximum heart rate or reserve heart rate. Nevertheless, the intermittency between the established heart rate percentages is not necessarily accompanied by the intermittent heart rate. In this sense, although there is an intermittent speed and inclination in the treadmill as well as resistance in the cycle ergometer, the elevated heart rate corresponding to the period of greatest intensity remains almost the same during periods of low intensity. In summary, HIIT would have a higher number of heartbeats compared to MICT, when maintaining high heart rate is disregarded. This may explain the gains made by HIIT. Therefore, considering and matching the number of heartbeats performed per training session in both models seems to be a more appropriate way to compare the two training protocols.

On the other hand, there appears to be a superiority of HIIT with respect to vascular endothelium-dependent adaptations. In this case, HIIT would have a greater effect on blood pressure reduction, both after a single training session and over the long term [15-18]. This action would be due to the greater release of endotheliumderived relaxing factors, mainly nitric oxide, when compared to MICT. This vascular advantage is explained by the higher cardiac demand during the higher intermittent period, which leads to a higher elevation of systolic blood pressure, and consequently, increased shear stress in the vascular endothelium.

Additionally, it is noteworthy that HIIT has attracted new supporters and uses as a marketing strategy the shortened average time per session. Although some studies have reported its efficacy and safety [19-22], in some cases, HIIT protocols may induce cardiac risks, as their methodology employs alternating high-intensity heartbeat interspersed with "passive" recovery periods. However, during this passive phase, there is only a slight reduction in heart rate, especially in those individuals with low cardiorespiratory fitness. This procedure might 
induce risks since venous return is impaired by interruption of muscle pump stimulation (gastrocnemius and soleus). This phase may predispose to major cardiovascular complications resulting from the abrupt drop in cardiomyocyte oxygenation due to the reduction in cardiac index.

\section{Conclusion}

In summary, our comments emphasize that considering and matching the number of heartbeats performed per training session in both models seems to be a more appropriate way to compare the two training protocols HIIT and MICT. Furthermore, we highlighted the procedures and care needed to prescribe HIIT in order to obtain greater gains and safety for the general population. Finally, all patients should also be examined by a cardiologist, who can assess the clinical condition, medication use, and the results of cardiological assessments performed prior to the start of any physical exercise protocol.

\section{Abbreviations \\ HIIT: High-intensity interval training; MICT: Moderate-intensity continuous training}

\section{Acknowledgements}

Not applicable.

\section{Authors' Contributions}

JALR contributed to the study design and wrote the manuscript; SVP and TPF contributed to the study design. ACG and HCDS supervised the study and was involved in the design. All authors read and approved the final manuscript.

\section{Funding}

No sources of funding were used.

\section{Availability of Data and Materials}

Not applicable.

Ethics Approval and Consent to Participate

Not applicable.

\section{Consent for Publication}

Not applicable

\section{Competing Interests}

Jhennyfer Aline Lima Rodrigues, Stella Vieira Philbois, Tábata de Paula Facioli, Ada Clarice Gastaldi, and Hugo Celso Dutra de Souza declare that they have no conflicts of interest relevant to the content of this article.

Received: 10 February 2020 Accepted: 30 June 2020

Published online: 15 July 2020

\section{References}

1. Lavie CJ, Ozemek C, Carbone S, Katzmarzyk PT, Blair SN. Sedentary behavior, exercise, and cardiovascular health. Circ Res. 2019;124:799-815.

2. Taylor JL, Holland DJ, Spathis JG, Betham KS, Wisløff U, Keating SE, Coombes JS. Guidelines for the delivery and monitoring of high intensity interval training in clinical populations. Prog Cardiovasc Dis. 2019;62:140-6.

3. Weston KS, Wisløff $U$, Coombes JS. High-intensity interval training in patients with lifestyle-induced cardiometabolic disease: a systematic review and meta-analysis. Br J Sports Med. 2014;16:1227-34.
4. Larsen I, Welde B, Martins C, Tjønna AE. High- and moderate-intensity aerobic exercise and excess post-exercise oxygen consumption in men with metabolic syndrome. Scand J Med Sci Sports. 2014;24:174-9.

5. Tjønna AE, Lee SJ, Rognmo Ø, Stølen TO, Bye A, Haram PM, et al. Aerobic interval training versus continuous moderate exercise as a treatment for the metabolic syndrome: a pilot study. Circulation. 2008;18:346-54.

6. Thum JS, Parsons G, Whittle T, Astorino TTA. High-intensity interval training elicits higher enjoyment than moderate intensity continuous exercise. PLoS One. 2017;12(1):e0166299.

7. Ghardashi-Afousi A, Holisaz MT, Shirvani H, Pishgoo B. The effects of lowvolume high-intensity interval versus moderate intensity continuous training on heart rate variability, and hemodynamic and echocardiography indices in men after coronary artery bypass grafting: a randomized clinical trial study. ARYA Atheroscler. 2018;14:260-71.

8. Alansare A, Alford K, Lee $S$, Church T, Jung HC. The effects of high-intensity interval training vs. moderate-intensity continuous training on heart rate variability in physically inactive adults. Int J Environ Res Public Health. 2018; 15:1-10.

9. Ramírez-Vélez R, Hernandez-Quiñones, Tordecilla-Sanders A, Alvarez C, Ramirez-Campillo R, Izquierdo M, et al. Effectiveness of HIIT compared to moderate continuous training in improving parameters in inactive adults. Lipids Health Dis. 2019;18(1):42-7.

10. Wisløff U, Støylen A, Loennechen JP, Bruvold M, Rognmo Ø, Haram PM, et al. Superior cardiovascular effect of aerobic interval training versus moderate continuous training in heart failure patients: a randomized study. Circulation. 2007:115:3086-94.

11. Currie KD, Rosen LM, Millar PJ, McKelvie RS, MacDonald MJ. Heart rate recovery and heart rate variability are unchanged in patients with coronary artery disease following 12 weeks of high-intensity interval and moderate-intensity endurance exercise training. Appl Physiol Nutr Metab. 2013;38:644-50.

12. Koufaki P, Mercer TH, George KP, Nolan J. Low-volume high-intensity interval training vs continuous aerobic cycling in patients with chronic heart failure: a pragmatic randomised clinical trial of feasibility and effectiveness. J Rehabil Med. 2014;46:348-56.

13. Ramos JS, Dalleck LC, Borrani F, Beetham KS, Mielke Gl, Dias KA, et al. Highintensity interval training and cardiac autonomic control in individuals with metabolic syndrome: a randomized trial. Int J Cardiol. 2017;15:245-52.

14. Esfandiari S, Sasson Z, Goodman JM. Short-term high intensity interval and continuous moderate-intensity training improve maximal aerobic power and diastolic filling during exercise. Eur J Appl Physiol. 2014;114:333-43.

15. Leung FP, Yung LM, Laher I, Yao X, Chen ZY, Huang Y. Exercise, vascular wall and cardiovascular diseases. Sports Med. 2008;38:1009-24.

16. Fernandes T, Gomes-Gatto CV, Pereira NP, Alayafi YR, Neves VJ, Oliveira EM. NO signaling in the cardiovascular system and exercise. Adv Exp Med Biol. 2017:211-45.

17. Boff W, Silva AM, Farinha JB, Rodrigues-Krause J, Reischak-Oliveira A, Tschiedel B, et al. Superior effects of high-intensity interval vs. moderateintensity continuous training on endothelial function and cardiorespiratory fitness in patients with type 1 diabetes: a randomized controlled trial. Front Physiol. 2019:10:450-9.

18. Hsu CC, Fu TC, Yuan SS, Wang CH, Liu MH, Shyu YC, et al. High-intensity interval training is associated with improved long-term survival in heart failure patients. J Clin Med. 2019;8:409-16.

19. O'Connor CM, Whellan DJ, Lee KL, Keteyian SJ, Cooper LS, Ellis SJ, et al. Efficacy and safety of exercise training in patients with chronic heart failure HF-ACTION randomized controlled trial. JAMA. 2009;301(14):1439-50.

20. Ellingsen $\varnothing$, Halle M, Conraads V, Støylen A, Dalen H, Delagardelle C, et al. SMARTEX Heart Failure Study (Study of Myocardial Recovery After Exercise Training in Heart Failure) Group, High-intensity interval training in patients with heart failure with reduced ejection fraction. Circulation. 2017;135:839-49.

21. Ding R. Exercise-based rehabilitation for heart failure: Clinical Evidence. Adv Exp Med Biol. 2017;1000:31-49.

22. Masson GS, Borges JP, Silva PPS, Nóbrega ACL, Tibiriçá E, Lessa MA. Effect of continuous and interval aerobic exercise training on baroreflex sensitivity in heart failure. Auton Neurosci. 2016;197:9-13.

\section{Publisher's Note}

Springer Nature remains neutral with regard to jurisdictional claims in published maps and institutional affiliations. 